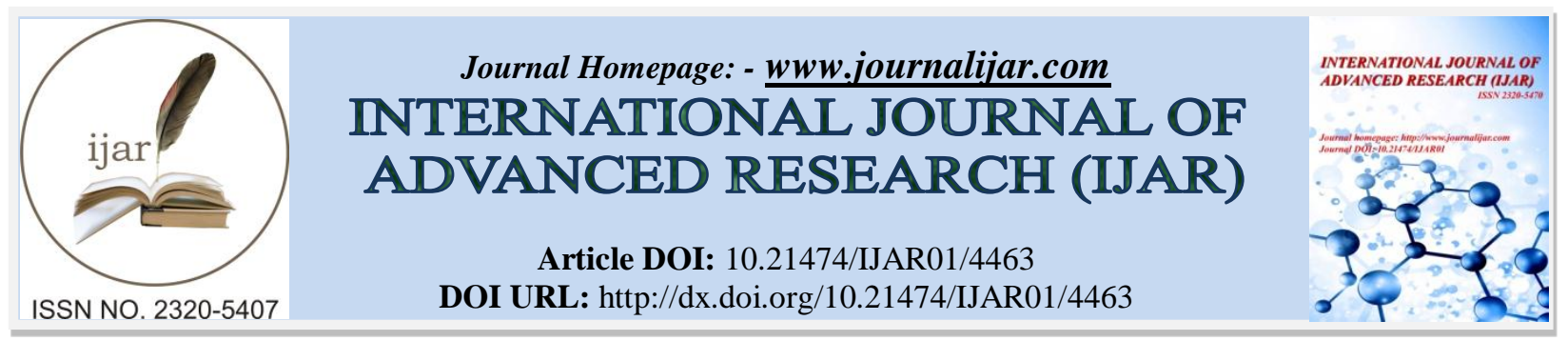

RESEARCH ARTICLE

\title{
COMPARATIVE STUDY OF SUGAR CONTENT FROM DIFFERENT FRUIT JUICES USING SACCHAROMYCES CEREVISIAE.
}

Indu Mehta ${ }^{1}$ and Nidhi Mittal ${ }^{2}$.

1. Department of Zoology, GGDSD College, Sector 32, Chandigarh.

2. Department of Biochemistry, GGDSD College, Sector 32, Chandigarh.

\section{Manuscript Info}

Manuscript History

Received: 12 April 2017

Final Accepted: 14 May 2017

Published: June 2017

Key words:-

Saccharomyces cerevisiae, fermentation, concentration.

\begin{abstract}
Production of Ethanol fermented from renewable sources for fuel or fuel additives is known as bioethanol. Since the need of bioethanol has been increasing, its production must be increased using cheaper and eco friendly raw materials. The production mainly utilizes three types of raw materials- sugar juice, starchy crops, and lignocellulosic materials. Several factors that influence the process for bioethanol production are temperature, $\mathrm{pH}$ and sugar concentration. Sugar accumulation in fruits is another important factor which has great impact on the amount of alcohol in wine. In addition to making bioethanol, the measurement of sugar content also allows to control the alcohol content in the wine. In this study, we have compared the content efficiency of sugar produced by fermentation process from different fruits juices such as watermelon (citron limon), mango (mangifera indica), lemon (prunus avium), pine apples (citrus sinesis) and mosami (citrus limetta). Saccharomyces cerevisiae is used in the fermentation process as it converts sugar with oxygen to give carbon dioxide. The study focuses on the status of glucose in various fruit juices in the presence and absence of yeast.
\end{abstract}

Copy Right, IJAR, 2017,. All rights reserved.

\section{Introduction:-}

Humans have fermentations techniques for the production of bread, wine and beer [1, 2]. Fermentation is done by yeast and some types of bacteria [3,4]. These microorganisms convert sugar into alcohol and carbon dioxide. Ethanol fuel has long been seen as a clean alternative fuel to petrol. However in the heated debate researchers have hit upon a novel idea i.e. using fruit to make ethanol. Ethanol an important biofuel, having high calorific value has the added advantage of being less polluting than most sources of energy that are in use today $[5,6]$.

India is the second largest producer of fruits in the world [7] which accounts for 30 million tones out of this seventytwo per cent of fruit waste due to lack of proper retailing and adequate storage capacity. Very little of fruit is exported in the absence of adequate processing and refrigeration/storage/cold chain facilities the situation is made worse by callous and antiquated post-harvesting practices, a staggering quantity of the produce rots in the fields or dangerously decays while in the process of transportation, storage and in the last leg of reaching the consumer [7].

The cheapest and easily available source for the production of bioethanol is fruit sugar. It is a potential energy source, from which ethanol can be obtained [8,9]. Approximately $80 \%$ of world supply of alcohol is produced by 
fermentation of sugar and starch containing crops or byproducts from industries based on such crops. Among the widely used substrates for ethanol production are the molasses of sugarcane and sugar beet. Several studies have shown that sugar based ethanol reduces greenhouse gases by 86 to $90 \%$ [6, 8]. Sugar-based bioethanol is a simple process and requires one step less than starch-bioethanol, this is because they are ready for conversion with limited pre-treatments as compared with starchy or cellulosic material.

Keeping in view the advantages of using fruits as an alternative source of ethanol production and the content of sugar controlling the amount of alcohol in wine, the present study focuses on the status of glucose in various fruit juices such as watermelon (citron limon), mango (mangifera indica), lemon (prunus avium), pine apples (citrus sinesis) and mosami (citrus limetta) in the presence and absence of yeast. Dried yeast is used for the experimental purpose to see the effect of yeast on the extent of fermentation of different fruit juices. The estimation of sugar in different fruit juices has been done by DNS method with and without adding yeast [10].

\section{Materials:-}

- Fruit Juices: Fruit juices were purchased fresh (mango, mosami, watermelon, pineapple and lemon) from the local market of Chandigarh.

- Dry Yeast: Dry yeast was purchased.

This study is carried out in the laboratory of Zoology Department GGDSD COLLEGE sector 32 Chandigarh.

\section{Methods:-}

\section{Preparation of solutions:-}

1. Glucose Stock Solution :- $0.1 \mathrm{gm} / 10 \mathrm{~mL}$, which was further diluted.

2. Dinitrosalicylic Acid Reagent (DNS Reagent) :- $1 \mathrm{gm}$ in $100 \mathrm{~mL} 1 \% \mathrm{NaOH}$.

3. Rochelle Salt Solution (Sodium Potassium Tartrate) :- $40 \mathrm{gm}$ in $100 \mathrm{~mL}$ distilled water i.e. $40 \%$.

4. Yeast Stock Solution: - $1 \mathrm{gm} / 10 \mathrm{~mL}$

\section{Procedure for glucose estimation:-}

From the stock, different concentrations of sugar were prepared i.e. $0.2 \mathrm{mg}, 0.4 \mathrm{mg}, 0.6 \mathrm{mg}, 0.8 \mathrm{mg}, 1.0 \mathrm{mg}, 1.5 \mathrm{mg}, 2.0$ $\mathrm{mg}, 2.5 \mathrm{mg}$ and $3.0 \mathrm{mg}$. the total volume is made upto to $3 \mathrm{~mL}$ by adding distilled water in all the test tubes. then $3 \mathrm{~mL}$ of DNS Reagent in each test tubeandPlaced in a boiling water bath for 5 to 8 minutes. $1 \mathrm{~mL}$ of $40 \%$ sodium potassium tartrate solution was added to each sample.Cooled down to room temperature and O.D. was taken on photometer at $540 \mathrm{~nm}$ after setting blank at 0.00 .

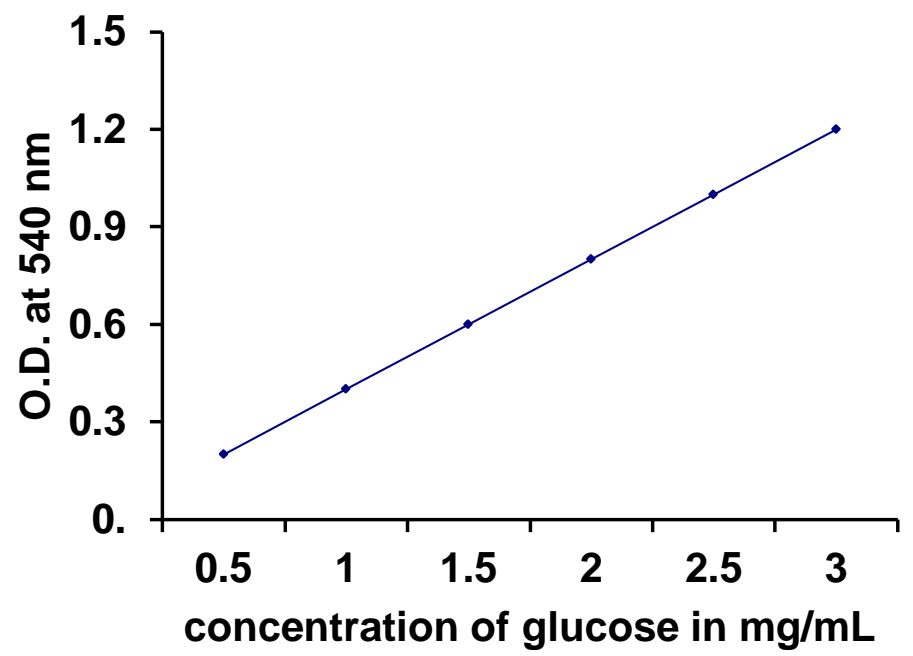

Fig. 1:- The above graph shows increasing concentration of glucose and its O.D.at 540nm.

\section{Estimation of glucose in fruit juices without adding yeast:-}

Glucose estimation for all the juices (shown in Table 1) was done as mentioned in the procedure. After standardization, 1:40 dilution for every juice was taken without adding yeast, as at higher concentration, the O.D. 
was out of range. Moreover, the amount of glucose was different in different fruit juices. Therefore 1:40 dilution was taken for all the juices.

Result:-

Table 1:- The above table shows the amount of glucose formed in different fruit juices at 1:40 dilution before adding yeast.

\begin{tabular}{|c|c|c|c|}
\hline S.No & JUICES & O.D. $(540 \mathrm{~nm})$ & CONC. OF GLUCOSE $(\mathrm{mg} / \mathrm{ml})$ \\
\hline 1. & Lemon (prunus avium) & 0.41 & 0.820 \\
\hline 2. & Pineapple (citrus sinesis) & 0.96 & 1.920 \\
\hline 3. & Mosami (citrus limetta) & 0.72 & 3.440 \\
\hline 4. & Watermelon (citron limon) & 1.84 & 1.980 \\
\hline 5. & Mango (mangifera indica) & 0.97 & 1.940 \\
\hline
\end{tabular}

\section{Estimation of glucose in fruit juices:-}

After adding yeast:-

Yeast stock solution of $1 \mathrm{gm} / 10 \mathrm{~mL}$ concentration was prepared. From the stock, $500 \mu \mathrm{g}$ of yeast per $5 \mathrm{ml}$ of each fruit juice was taken at 1:40 dilution as done before. It was then incubated at $37^{\circ} \mathrm{C}$ for 2 hours. Centrifuged at 5,000 rpm for 10 minute $3 \mathrm{~mL}$ of supernatant was taken. Glucose estimation was done for each fruit juice supernatant by DNS method as mentioned in the procedure (Table 2).

Table 2:- The above table shows the amount of glucose formed (in $\mathrm{mg} / \mathrm{ml}$ ) in different fruit juices at 1:40 dilution when incubated with yeast at $37^{\circ} \mathrm{C}$ for 2 hours.

\begin{tabular}{|c|c|c|c|}
\hline S.No. & JUICES & O.D. $(540 \mathrm{~nm})$ & CONC. OF GLUCOSE $(\mathrm{mg} / \mathrm{ml})$ \\
\hline 1. & Lemon (prunus avium) & 0.90 & 1.800 \\
\hline 2. & Pineapple (citrus sinesis) & 1.23 & 2.460 \\
\hline 3. & Mosami (citrus limetta) & 1.35 & 3.700 \\
\hline 4. & Watermelon (citron limon) & 1.87 & 3.740 \\
\hline 5. & Mango (mangifera indica) & 1.95 & 3.900 \\
\hline
\end{tabular}

\section{Estimation Of Glucose In Fruit Juices For Prolonged Incubation (48 Hours), After Adding Yeast:-}

Yeast was added in all the fruit juices as done before.Incubated at $37^{\circ} \mathrm{C}$ for 48 hours. Glucose estimation was done for each fruit juice supernatant by DNS method as mentioned in the procedure (Table 3).

Table 3:- The above table shows the amount of glucose formed (in $\mu \mathrm{g}$ ) in different fruit juices at 1:40 dilution when incubated with yeast at $37^{\circ} \mathrm{C}$ for 48 hour.

\begin{tabular}{|c|c|c|c|}
\hline S.No. & JUICES & O.D. $(540 \mathrm{~nm})$ & CONC. OF GLUCOSE $(\mu \mathrm{g})$ \\
\hline 1. & Lemon (prunus avium) & .04 & 80 \\
\hline 2. & Pineapple (citrus sinesis) & .04 & 80 \\
\hline 3. & Mosami (citrus limetta) & .01 & 60 \\
\hline 4. & Watermelon (citron limon) & .02 & 40 \\
\hline 5. & Mango (mangifera indica) & & 60 \\
\hline
\end{tabular}

\section{Results and Discussion:-}

The present study was done to see the presence of glucose in various fruit juices in the presence and absence of yeast. For this, firstly, the estimation of glucose in different fruit juices without adding yeast was done by DNS method. From the O.D., concentration of glucose was calculated in each fruit juice. Then estimation of glucose in each fruit juice was done after adding yeast and incubating at $37^{\circ} \mathrm{C}$ for 2 hours.

The results showed that the concentration of glucose was enhanced after the addition of yeast. Table 2 shows the increase in glucose without yeast and after adding yeast. In order to see the status of glucose formed after prolonged incubation with yeast, fruit juices were incubated at $37^{\circ} \mathrm{C}$ along with the yeast for much longer time i.e. 48 hours. The result (shown in table 3) depict that there is remarkable decline in the glucose; probably because the yeast breaks down sugar and turns it into ethyl alcohol and carbon dioxide gas in anaerobic conditions. Thus, it is concluded that there is tremendous increase in the amount of glucose when fruit juices were incubated in the presence of yeast, which later gets consumed probably for ethanol production. 
The production of ethanol from these fruits can be further improved by using suitable technologies i.e., using genetically engineered strains that are capable of converting multiple sugars in to ethanol. .

\section{Conclusion:-}

The result of this work has shown the sugar content of different fruit juices in the presence and absence of yeast for different time Intervals. The results showed that the various fruits can serve as the raw materials for biofuel production and further studies can be done to make it cost effective, like the use of waste material left after preparation of juices. Since this process does not yield any toxic compounds hence it can be run as a small scale industry.

\section{References:-}

1. J. Robinson (ed) "The Oxford Companion to Wine" Third Edition pg 267-269 Oxford University Press 2006 ISBN 0198609906.

2. Jordao, A., M, Vilela., A And Cosme, F(2015) From sugar of grape to Alcohol of Wine: Sensorial Impact of Alcohol in Wine. Beverages 1, 292-310.

3. "The History of Bread Yeast". British Broadcasting Corporation. Retrieved December 24, 2006.

4. "Fermented fruits and vegetables. A global perspective". FAO Agricultural Services Bulletins - 134. Retrieved on 2007-01-28.

5. Suhas V Bhandari, Arun Panchapakesan., Naveen Shankar and H G Ashok Kumar, Production of Bioethanol From Fruit Rinds by Saccharification and Fermentation . Department of Biotechnology, RV College of Engineering, Mysore Road, Bangalore - 560059 Volume 2 Issue 6 pp 362-365 September 2013.

6. Venkatachalapathy Girish, Krishnappa Ravi Kumar and Sirangala Thimmappa Girisha, Estimation of sugar and bio ethanol from different decaying fruits extract. Advances in Applied Science Research, 2014, 5(1):106-110.

7. Akin-Osanaiye, B. C., Nzelibe, H.C., and Agbaji, A.S., "Ethanol production from Carica papaya (pawpaw) fruit wate", Asian Journal of Biochemistry, vol 3. (3), pp. 188-193, 2008.

8. Sandesh Babu1, K.M.Harinikumar2, Ravi Kant Singh and Aditi Pandey, Optimization of Bioethanol Production from Fruit Wastes using Isolated Microbial Strains Vol5, Issue4, 2014, p598-604

9. Reddy, V., "Production of ethanol from mango (Mangifera indica L) fruit juice fermentation", Research Journal of Microbiology, vol.2, (10), pp.763-769, 2007.

10. Miller GL (1959), Use of dinitrosalicylic acid reagent for determination of reducing sugar. Anal Chem. 31 (3): 426-428. 